\title{
LONG-TERM RESULTS OF SACRAL RHIZOTOMY FOR URETERAL REFLUX IN THE SPINAL CORD INJURED
}

\author{
By E. L. Cashion, M. D., F.A.C.S. and Benjamin A. Moeller, M.D., F.A.C.P. \\ Veterans Administration Hospital, Memphis, Tennessee: Neurosurgical Section, Spinal Cord \\ Injury Service: and Department of Neurosurgery, University of Tennessee College of Medicine, \\ Memphis, Tennessee
}

\section{INTRODUCTION}

RENAL failure is a leading cause of death in patients with a spinal cord injury (Bors \& Comarr, I97I). Pyelonephritis, the most frequent complication in these patients, contributes to this failure. Pyelonephritis is considered to be secondary to vesicoureteral reflux in most cases (Smith, I969). The incidence of demonstrable reflux with urinary tract infection is up to 50 per cent. Reflux may be due to congenital anomalies, vesical neck obstruction, inflammation secondary to bladder stones (Smith, 1970) or neurogenic disorders (Hutch, 1958; Bors \& Comarr, I97I). It is a dynamic process and may disappear spontaneously but constant reflux leads to worse complications than inconstant reflux (Talbot, 1967).

In patients with a spinal cord injury, reflux may be contributed to by a small, hypertonic, heavily trabeculated bladder (Hutch, 1958; Bunts, 1970). In 27 per cent of those with an upper motor neuron lesion, reflux developed at some time in their illness (Bors \& Comarr, I97I, 330).

If a small hypertonic bladder contributes to ureteral reflux, enlarging the bladder capacity and reducing its hypertonicity should reduce the incidence of pyelonephritis and hydroureteronephritis (Scheibert, I954; Hutch, I958, 88-89; Bunts, 1970). This should be accomplished by sacral rhizotomy as the motor innervation of the bladder is through these nerves (Smith, I970).

\section{CASES}

For 20 years sacral rhizotomies had been carried out to reduce ureteral reflux at the Spinal Cord Injury Center, Veterans Administration Hospital, Memphis, Tennessee. Eleven cases, on whom long-term follow-up is available, have been done specificially for reflux. All patients had a complete transverse myelopathysix cervical, five thoracic. No rhizotomies were carried out until at least 30 months post-injury; most were longer. All patients had had repeated episodes of pyelonephritis. All had reflux on cystogram except two in which it was a clinical diagnosis. All patients have been followed for at least six months, most for years.

All rhizotomies were done bilaterally. Extradural section of $\mathrm{S}_{2}$ through $\mathrm{S}_{4}$ was done in six patients. In five, intradural section was done with $S_{2}$ through $\mathrm{S}_{5}$ being sectioned in two; $\mathrm{S}_{2}$ through $\mathrm{S}_{4}$ in two; $\mathrm{S}_{3}$ through $\mathrm{S}_{4}$ in one. These selective rhizotomies were done after it was shown that the roots sectioned contributed almost all the innervation of the bladder as manifested by bladder contraction on stimulation of these nerve roots. In one case there was marked perineal relaxation. There was no case of prolapse of the rectum. 


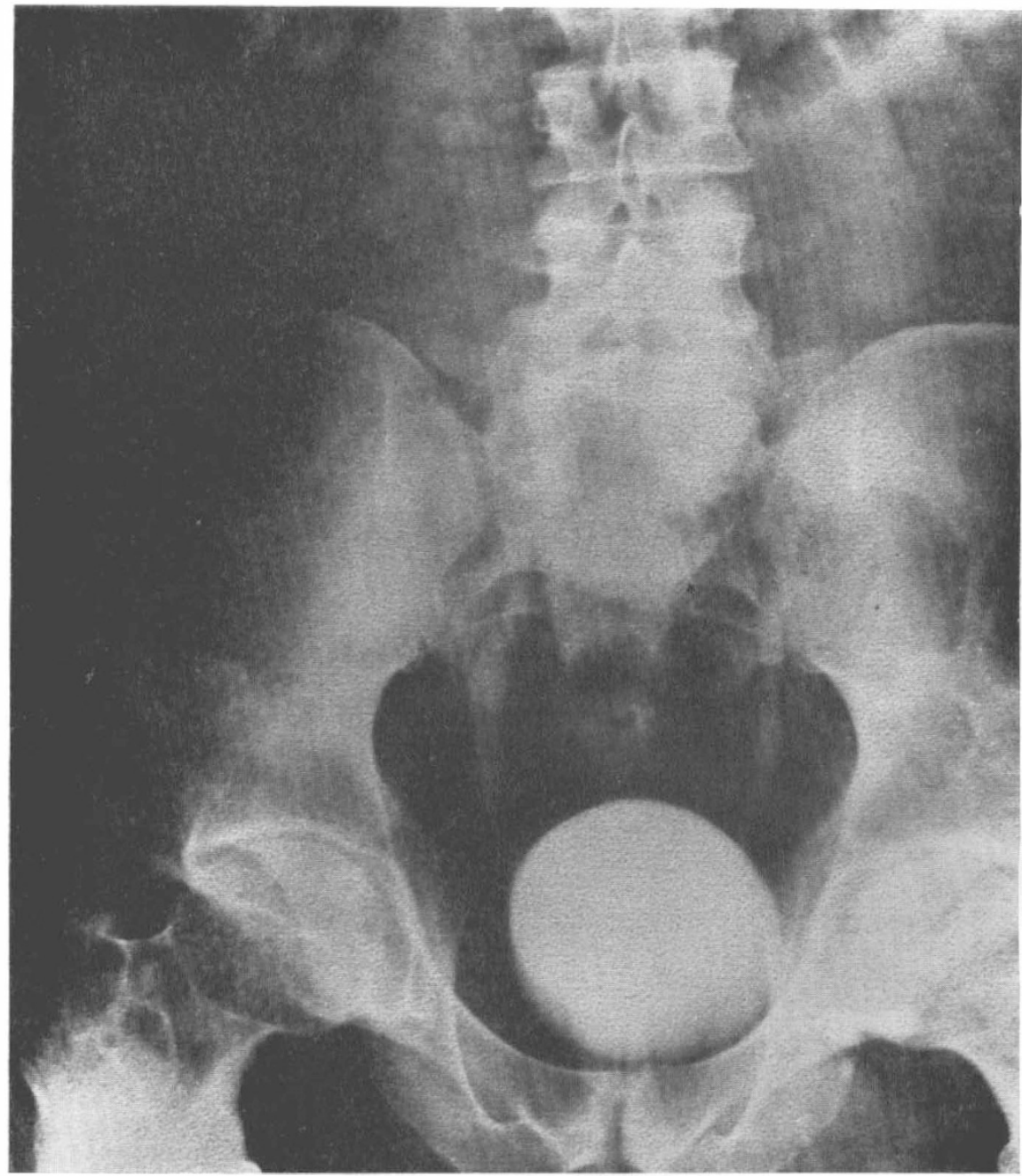

FIG. I

Cystogram eight months after bilateral section of $S_{2}, S_{3}$, and $S_{4}$. Note bilateral reflux.

\section{RESULTS}

Five patients had bilateral reflux on cystogram three to ten years after surgery (fig. I). These cases are considered as failures. One patient died seven years postoperatively with pyelonephritis. One patient is alive seven years postoperative but continues to have repeated episodes of urinary tract infection so his case is considered a failure.

One patient has no reflux on cystogram four years postoperative, but continues with episodes of pyelonephritis so his case is considered slightly improved. 
TABLE I

Bladder capacity, measured at cystometrogram, before and after sacral rhizotomy for ureteral reflux

\begin{tabular}{|c|c|c|}
\hline $\begin{array}{c}\text { Preoperative } \\
\text { capacity }\end{array}$ & $\begin{array}{c}\text { Postoperative } \\
\text { capacity }\end{array}$ & $\begin{array}{c}\text { Length of follow-up } \\
\text { (years) }\end{array}$ \\
\hline & $\begin{array}{l}\text { Increased } \\
\text { I50 cc. }\end{array}$ & \\
$40 \mathrm{cc}$. & I00 cc. & $3 \frac{1}{2}$ \\
$50 \mathrm{cc}$. & I50 cc. & $\frac{9}{12}$ \\
$50 \mathrm{cc}$. & $220 \mathrm{cc}$. & $\frac{7}{12}$ \\
I00 cc. & Same & \\
& I00 cc. & 4 \\
I00 cc. & Decreased \\
& $30 \mathrm{cc}$. & 9 \\
\hline
\end{tabular}

Three patients seem to have fewer episodes of pyelonephritis than before surgery although this is difficult to evaluate. These three cases are considered to have an excellent result. One of these had reflux on cystogram I4 years after surgery.

The bladder capacity was increased in four of the patients, stayed the same in one, decreased in one (Table I). Only one of these cases, where the bladder capacity was increased, is in the excellent result group.

\section{DISCUSSION}

Long-term results of sacral rhizotomy for ureteral reflux in patients with a spinal cord injury are difficult to evaluate On the basis of our results, of only three out of I I patients obtaining an excellent result from surgery, we have discontinued the procedure. The relative ineffectiveness of sacral rhizotomy in treating ureteral reflux and chronic recurrent pyelonephritis may be due to lack of reduction of reflux despite extensive denervation. It may be that ureteral reflux, which is a poorly understood phenomenon, is not related to the repeated episodes of pyelonephritis these patients experience. Recurrent infections may have altered the structures of the genito-urinary tract beyond repair.

Other reasons for failure of rhizotomy may be related to the bladder. In several of our cases cystometrograms done after surgery showed a small hypertonic bladder. This post-rhizotomy pressure greater than expected of a lower motor neuron bladder may be due to stimulation over the sympathetic presacral plexus. Another evidence of lack of denervation despite extensive rhizotomy was the presence of a bulbocavernosus reflux in two cases. This has been reported by others (Comarr \& Bors, 1955). 


\section{CONCLUSIONS}

Extensive sacral rhizotomy as treatment of ureteral reflux has been done in I I patients with a complete transverse myelopathy due to trauma. It is difficult to evaluate the results but only three of the I I had an excellent result. The operation as performed, is not indicated! This is because the indications used have not been a correct guide for the procedure. In the past we considered for surgery those patients who had a small hypertonic bladder with ureteral reflux on cystogram. It may be that a small hypertonic bladder is not a major contributing factor to reflux. Reflux as seen on cystogram may not be indicative of a serious disorder. Another reason for failure may be that there is innervation of the bladder other than the lower sacral nerves, or there is return of tone to the bladder.

\section{SUMMARY}

A study of the results of sacral rhizotomies done over 20 years to reduce ureteral reflux at the Spinal Cord Injury Center, Veterans Administration Hospital, Memphis, Tennessee, leads to the conclusion that this procedure is not indicated.

\section{RÉsUMÉ}

Une étude des résultats de radicotomies sacrales réalisées sur une période de vingt ans pour réduire le reflux uretéral au Centre des lésions de la moelle épinière, Veterans Administration Hospital, Memphis, Tennessee, Etats-Unis, mène a la conclusion que cette méthode n'est pas indiquée.

\section{ZUSAMMENFASSUNG}

Das Resultat einer Analyse von sakralen Rhizotomien, die in den letzten 20 Jahren für die Behandlung von Reflux ausgeführt wurden, ist, dass diese Operation nicht indiziert ist.

\section{REFERENCES}

Bors, E. \& ComarR, A. E. (I97I). Neurological Urology. S. Karger, Basel.

BunTS, R. C. (1970). Surgery of urinary tract dysfunction due to disease of injury of the nervous system. Urological Surgery, 4 th edition, ed. A. I. Dodson, 338-356. C. V. Mosby, Saint Louis.

ComarR, A. E. \& Bors, E. (1955). Further observations on vesicoureteral reflux. F. Urol. 74, 59-66.

Hutch, J. A. (1958). The Ureterovesical Junction. University of California Press, Berkeley.

Meirowsky, A. M., Scheibert, C. D. \& Hinchey, T. R. (I950). Studies on the sacral reflex arc in paraplegia; response of the bladder to surgical elimination of sacral nerve impulses by rhizotomy. F. Neurosurg. 7, 33-38.

SCHEIBERT, C. D. (1954). Sacral nerve interruption in paraplegia. Proceedings of Third Annual Clinical Paraplegia Conference, VA Hospital, West Roxbury, Mass., 24-29.

TALbOt, H. S., MAhONEY, E. M., JARRETT, J. E. et al. (1967). Uretero-vesical dynamics in relation to reflux. Paraplegia, 5, 97-103.

SMITH, D. R. (I969). General Urology, 6th edition, p. I23. Lange Medical Publications, Los Altos, Calif.

SMITH, D. R. (I970). Vesicoureteral reflux and other abnormalities of the ureterovesical junction. Urology, I, eds. M. F. Campbell and J. H. Harrison, 3rd edition, 349-397. W. B. Saunders, Philadelphia. 